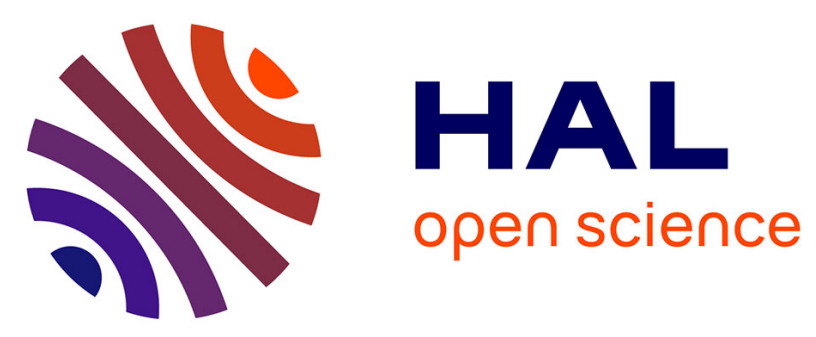

\title{
The safety of mineralocorticoid antagonists in maintenance hemodialysis patients: two steps forward
}

Patrick Rossignol, Luc Frimat, Faiez Zannad

\section{To cite this version:}

Patrick Rossignol, Luc Frimat, Faiez Zannad. The safety of mineralocorticoid antagonists in maintenance hemodialysis patients: two steps forward. Kidney International, 2019, 95 (4), pp.747-749. 10.1016/j.kint.2018.12.006 . hal-02510924

\section{HAL Id: hal-02510924 \\ https://hal.univ-lorraine.fr/hal-02510924}

Submitted on 22 Oct 2021

HAL is a multi-disciplinary open access archive for the deposit and dissemination of scientific research documents, whether they are published or not. The documents may come from teaching and research institutions in France or abroad, or from public or private research centers.
L'archive ouverte pluridisciplinaire HAL, est destinée au dépôt et à la diffusion de documents scientifiques de niveau recherche, publiés ou non, émanant des établissements d'enseignement et de recherche français ou étrangers, des laboratoires publics ou privés.

\section{(ㄷ)(1) $\$$}

Distributed under a Creative Commons Attribution - NonCommerciall 4.0 International 
The safety of mineralocorticoid antagonists in maintenance hemodialysis patients: Two steps forward

Patrick Rossignol $^{1}, \mathrm{MD}, \mathrm{PhD}$, Luc Frimat ${ }^{2}, \mathrm{MD}, \mathrm{PhD}$, Faiez Zannad ${ }^{1}$, MD, PhD

1. Université de Lorraine, CIC 1433, U 1116, Inserm, CHRU de Nancy, and FCRIN INI-CRCT (Cardiovascular and Renal Clinical Trialists), Nancy, France

2. Nephrology department, CHRU de Nancy, Université de Lorraine and FCRIN INI-CRCT (Cardiovascular and Renal Clinical Trialists), Nancy, France

Correspondence: Pr. Patrick Rossignol

Centre d'Investigations Cliniques-INSERM CHRU de Nancy

Institut lorrain du Cœur et des Vaisseaux Louis Mathieu

4 rue du Morvan

54500 Vandoeuvre Lès Nancy

France

Tel : +33 383157320

Fax : +33 383157324

p.rossignol@chru-nancy.fr 
Abstract: The Spin-D and MiREnDA trials taken together provide the reassuring demonstration that spironolactone up to $25 \mathrm{mg} / \mathrm{d}$ is reasonably safe, and that provided maintenance hemodialysis patients are properly monitored and investigators use a per-protocol therapeutic algorithm to manage hyperkalemia. These results should encourage and reassure the investigators of the two currently ongoing large international, major outcome clinical trials, both of which are using spironolactone up to $25 \mathrm{mg} / \mathrm{d}$ : ACHIEVE (NCT03020303) and ALCHEMIST (NCT01848639).

Keywords: hemodialysis, aldosterone

In patients with end-stage renal disease (ESRD) on chronic dialysis, cardiovascular (CV) mortality is 10 to 20 times higher than in the general population and, among adults younger than 45 years, mortality rates are approximately 100 times higher than in the general population ${ }^{1}$. Hence, treatments to improve survival, and more specifically cardiovascular outcomes, in this population are greatly needed. Disappointingly, few large outcome trials have been conducted specifically in the ESRD populations on dialysis: in a recent review, a less than two-page table was more than sufficient to summarize key randomized controlled trials and metaanalyses assessing mortality in ESRD as a primary endpoint! ${ }^{2}$. Few trials have reported beneficial treatment effects on cardiovascular outcomes, while many more were inconclusive due to study design limitations (e.g. open-label, small sample size, suboptimal target population) ${ }^{3}$.

Of note, a meta-analysis suggested that antihypertensive drugs as a whole may improve CV outcomes in normotensive and hypertensive patients with ESRD on chronic hemodialysis $(\mathrm{HD})^{4}$. Mineralocorticoid receptor antagonists (MRAs) are one 
of the cornerstones of therapy in heart failure with reduced ejection fraction, except in patients with hyperkalemia and/or estimated glomerular filtration rate below 30 $\mathrm{ml} / \mathrm{min} / 1.73 \mathrm{~m}^{2} 5$. However, practical implementation of high-grade trial evidence is hindered by physicians' apprehension regarding the hyperkalemia risk, inherently associated with renin-angiotensin aldosterone system (RAAS) blockade. Based on experimental and observational clinical data, it is clear that the RAAS plays a key role in the cardiovascular damage associated with chronic kidney disease. Mineralocorticoid receptors are expressed not only in the epithelium but also in several nonepithelial sites (including the brain, heart, and vasculature), in addition to the fact that cardiovascular tissues can also synthesize aldosterone. Whether MRA may exhibit live-saving properties in chronic ESRD on HD is still unknown, despite the provocative results of an open-label randomized trial ${ }^{5}$. Upstream, relatively smallsized and short-term trials suggested an acceptable safety profile related to potassium and blood pressure, and even suggested a beneficial effect on cardiovascular structure and function ${ }^{6}$.

In this issue of the Journal, Charytan et al. ${ }^{7}$ report results of the randomized placebocontrolled double-blind Safety and Cardiovascular Efficacy of Spironolactone in Dialysis-Dependent ESRD (Spin-D) trial. This was an early-phase dose-ranging safety and efficacy trial, with the MRA spironolactone $(12.5,25,50 \mathrm{mg} / \mathrm{d})$ in 129 chronic hemodialysis patients followed for up to 36 weeks. This is the first ever such trial reported in the hemodialysis setting and the authors should be complimented for the optimal design and conduct of the trial. In $125(97 \%)$ of the 129 patients, it was possible to escalate the dose in accordance with the protocol, while $27(21 \%)$ patients permanently discontinued the study drug, mainly for hyperkalemia (44\%). The authors rightly conclude that spironolactone was well tolerated compared with 
placebo. Indeed, for the two co-primary safety outcomes of potassium concentration $>6.5 \mathrm{mEq} / \mathrm{L}$ and hypotension requiring hospitalization or emergency room visit, there was no overall difference between spironolactone and placebo groups. However, there was evidence of increasing hyperkalemia and hypotension rates with higher dosages (especially $50 \mathrm{mg} / \mathrm{d}$ ). Serum potassium was measured at 3-5 days and 2 weeks after study drug initiation or dose increase, as well as monthly throughout the duration of treatment. A concomitant hyperkalemia management algorithm was also implemented, encompassing potential corrective actions (discontinuation or reduction of angiotensin converting enzyme inhibitor or angiotensin receptor blocker, dietary counseling, reduction of dialysate potassium concentrations to $2 \mathrm{mEq} / \mathrm{L}$, reduction of study drug, etc.). Efficacy outcomes were considered exploratory. There were no convincing improvements in cardiac function (diastolic function, as assessed by the primary efficacy endpoint of changes in mitral annular E' velocity using tissue Doppler index echocardiography) and structure. Left ventricular mass index, left ventricular ejection fraction, and left ventricular global longitudinal strain did not improve.

Also in this issue of the Journal, Hammer et al. ${ }^{8}$ report the effect of spironolactone 50 mg once daily $(n=50)$ or placebo $(n=47)$ on left ventricular mass (LVM) of 97 chronic hemodialysis patients randomized $1: 1$ in a double-blind manner. The primary efficacy endpoint of this effect of spironolactone on left ventricular mass in hemodialysis patients (the MiREnDa) trial was the change in LVM index (LVMi) from baseline to 40 weeks of treatment as determined by cardiac magnetic resonance imaging (MRI). This was an optimally-designed, conducted, and reported early-phase trial. Treatment with $50 \mathrm{mg}$ spironolactone had no significant effect on surrogate cardiovascular endpoints, using the gold standard MRI to assess left ventricular 
mass, left ventricular ejection fraction, and 24-h systolic or diastolic blood ambulatory pressure. However, $50 \mathrm{mg}$ spironolactone resulted in a significantly higher incidence of moderate hyperkalemia, as defined by pre-dialysis potassium levels 6.0-6.5 mmol/L (155 vs. 80 events, $P=0.034$ ), whereas severe hyperkalemia episodes (predialysis potassium levels $\geq 6.5 \mathrm{mmol} / \mathrm{L}$ ) were not significantly different between the two groups (spironolactone, 14 vs. placebo, 24 events, $P=0.225$ ). Of the 97 randomized patients, 77 took at least half a tablet of study medication for a minimum of 30 weeks, while the overall mean dose of spironolactone was $42 \mathrm{mg} /$ day. A therapeutic algorithm to manage hyperkalemia was indeed implemented, encompassing temporarily withholding study medication, down-titration $(25 \mathrm{mg} / \mathrm{d})$ followed by a possible re-uptitration, enabled by potassium measurement prior to every dialysis session.

As rightly stated by both groups, the neutral effect of spironolactone on cardiovascular structure and function reported in this two relatively short-term (9month studies) does not preclude that MRAs have the potential to improve long-term cardiovascular outcomes in ESRD. There is indeed no evidence that changes in the investigated cardiovascular intermediate phenotypes may reliably predict morbidity and mortality benefits in outcome trials in chronic hemodialysis. Furthermore, patients with well-preserved diastolic function and LVM (Spin-D) and a relatively modest (40\%) prevalence of left ventricular hypertrophy (MiREnDA) at baseline were enrolled, leaving little opportunity for improvement. Moreover, MRA may exhibit a beneficial effect independent and beyond decreasing LV mass, given their beneficial effects on cardiovascular remodeling, including fibrosis. Fibrosis, both in the heart and in the kidney, is the common consequence of inflammation- and oxidative stress-related endothelial dysfunction in aging, hypertension, diabetes mellitus and 
obesity, ultimately leading to cardiovascular disease, including atherosclerosis progression, heart failure, arrhythmias and chronic kidney disease ${ }^{9}$ (Figure).

Therefore, the intermediate endpoints used in the Spin-D and MiREnDA trials are not informative with regard to outcome, and the ultimate risk-benefit ratio can only be established when the ongoing outcome trials will deliver. However, the most compelling result of the Spin-D and MiREnDA trials taken together is the reassuring demonstration that spironolactone up to $25 \mathrm{mg} / \mathrm{d}$ is reasonably safe, and that provided patients are properly monitored and investigators use a per-protocol therapeutic algorithm to manage hyperkalemia. These results should encourage and reassure the investigators of the two currently ongoing large international, major outcome clinical trials, both of which are using spironolactone up to $25 \mathrm{mg} / \mathrm{d}$. The ALdosterone antagonist Chronic HEModialysis Interventional Survival Trial (ALCHEMIST, NCT01848639), is planning to recruit 825 high-risk chronic hemodialysis patients (i.e. presenting at least one of the following comorbidities, cardiovascular abnormalities or cardiovascular risk factors: left ventricular hypertrophy, left ventricular ejection fraction $<40 \%$, large QRS $>0.14 \mathrm{sec}$ or left bundle branch block; diabetes; history of cardiovascular disease, CRP $>5 \mathrm{mg} / \mathrm{l}$ for 3 months without documented infectious or neoplastic disease in progress). The primary composite endpoint is the time to onset of the first incident non-fatal myocardial infarction, acute coronary syndrome, hospitalization for heart failure, nonfatal stroke or cardiovascular-induced death. Over 620 patients have been enrolled in the ALCHEMIST trial to date. The Aldosterone bloCkade for Health Improvement EValuation in End-stage Renal Disease (ACHIEVE NCT03020303) is planning to recruit 2750 chronic hemodialysis or peritoneal dialysis patients ( $\geq 45$ 
years, or $\geq 18$ with a history of diabetes). The primary endpoint is death or hospitalization for heart failure.

The investigators and their respective research staffs and networks involved in these two double-blind placebo-controlled cardiovascular outcome trials of spironolactone $25 \mathrm{mg} / \mathrm{d}$ must be encouraged to put their best effort to complete enrolment and follow-up in both trials. Their academic sponsors, the oversight, safety and adjudication committees, the supporting patient advocacy groups, and above all, the already-enrolled patients must readily be thanked and congratulated for all their effort, since they strongly contribute toward filling the compelling gap in knowledge in this very high-risk population which, regrettably, is almost systematically excluded from major pharma outcome clinical trials. Chronic ESRD patients and the medical community worldwide are eagerly awaiting the results, which may change medical practices and improve patient outcomes.

\section{Disclosures:}

Patrick Rossignol: Personal fees (consulting) from Novartis, NovoNordisk, Relypsa, AstraZeneca, Grünenthal, Idorsia, Stealth Peptides, Fresenius, Vifor Fresenius Medical Care Renal Pharma, Vifor; lecture fees from Bayer and CVRx; cofounder of CardioRenal

Luc Frimat: Travel grants from Astellas, Fresenius, Novartis, Roche.

Faiez Zannad: Personal fees for Steering Committee membership from Janssen, Bayer, Pfizer, Novartis, Boston Scientific, Resmed, Takeda, General Electric, and 
Boehringer Ingelheim; consultancy for Amgen, CVRx, Quantum Genomics, Relypsa, ZS Pharma, AstraZeneca, GSK; founder of Cardiovascular Clinical Trialists (CVCT) and of CardioRenal.

\section{Acknowledgements:}

FZ and PR are supported by the French National Research Agency "Fighting Heart Failure" (ANR-15-RHU-0004), and the French PIA project «Lorraine Université d'Excellence » GEENAGE (ANR-15-IDEX-04-LUE) programs. The ALCHEMIST trial is sponsored by the CHRU de Brest, and is mainly funded by the French Programme Hospitalier de Recherche Clinique (PHRC-N). The authors thank Mr. Pierre Pothier for editing the manuscript.

Figure title: putative pathophysiological mechanisms and conditions targeted by mineralocorticoid receptor antagonism in chronic hemodialysis cardiovascular outcome trials

\section{References}

1. Rossignol P, Pitt B, Thompson A, et al. Roadmap for cardiovascular prevention trials in chronic kidney disease. Lancet 2016; 388: 1964-1966.

2. Ortiz A, Covic A, Fliser D, et al. Epidemiology, contributors to, and clinical trials of mortality risk in chronic kidney failure. Lancet 2014; 383: 1831-1843.

3. Rossignol P, Agarwal R, Canaud B, et al. Cardiovascular outcome trials in patients with chronic kidney disease: challenges associated with selection of patients and endpoints. Eur Heart J 2017. 
4. Agarwal R. Blood pressure and mortality among hemodialysis patients. Hypertension 2010; 55: 762-768.

5. Pitt B, Rossignol P. Mineralocorticoid receptor antagonists in patients with end-stage renal disease on chronic hemodialysis. J Am Coll Cardiol 2014; 63: 537-538.

6. Shavit L, Lifschitz MD, Epstein M. Aldosterone blockade and the mineralocorticoid receptor in the management of chronic kidney disease: current concepts and emerging treatment paradigms. Kidney Int 2012; 81: 955-968.

7. Charytan D, Himmelfarb J, Ikizler T, et al. Safety and Cardiovascular Efficacy of Spironolactone in Dialysis-Dependent ESRD (SPin-D): A Randomized, PlaceboControlled, Multiple Dosage Trial Kidney Int 2018.

8. Hammer F, Malzahn U, Donhauser J, et al. Effect of spironolactone on left ventricular mass in hemodialysis patients: the MiREnDa study - a randomized controlled trial. Kidney Int 2018.

9. Zannad F, Rossignol P. Cardiorenal Syndrome Revisited. Circulation 2018; 138: 929944. 


\section{Mineralocorticoid}

receptor antagonism

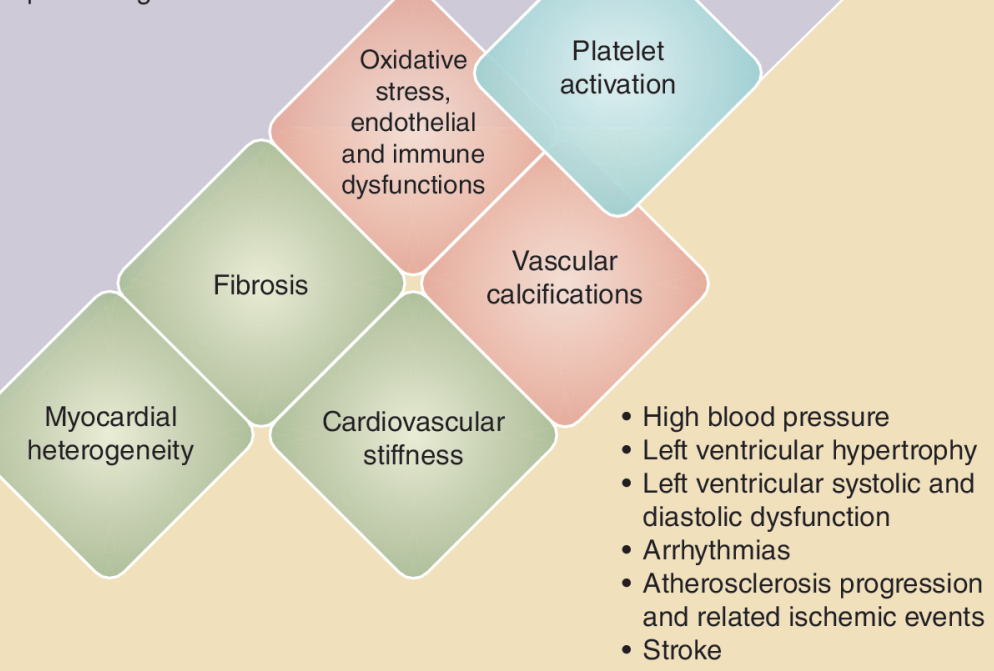

